\title{
Characteristics of People committing suicide in Medellín, Colombia
}

\author{
Carlos Palacio-Acosta ${ }^{1}$, Jenny García-Valencia ${ }^{2}$, Johanna Diago-García ${ }^{3}$, Claudia \\ Zapata $^{4}$, Juan Ortiz- Tobón ${ }^{5}$, Gabriel López-Calle ${ }^{6}$ y María López-Tobón ${ }^{7}$ \\ ${ }^{1}$ Médico, Especialista en Psiquiatría. M. Sc. Epidemiología. Instituto Nacional de Medicina Legal. \\ Facultad de Medicina, Universidad de Antioquia. Teléfono: (574) 2106090. E-mail: cpalacio@epm.net.co \\ ${ }^{2}$ Médica, Especialista en Psiquiatría. M. Sc. Epidemiología. Departamento de Psiquiatría, Facultad de \\ Medicina, Universidad de Antioquia. Teléfono: (574) 2131813. E-mail: jegava@epm.net.co \\ ${ }^{3}$ Médico. Departamento de Psiquiatría, Facultad de Medicina, Universidad de Antioquia. \\ E-mail: jpdiago@hotmail.com \\ ${ }^{4}$ Médico. Departamento de Psiquiatría, Facultad de Medicina, Universidad de Antioquia. E-mail: \\ claudiazapata101@yahoo.com.ar \\ ${ }^{5}$ Médico, Especialista en Psiquiatría. Departamento de Psiquiatría, Facultad de Medicina, Universidad de \\ Antioquia. E-mail: juanfot@hotmail.com \\ ${ }^{6}$ Médico, Especialista en Psiquiatría. Instituto Nacional de Medicina Legal. \\ E-mail: gabrieljlopez@epm.net.co \\ ${ }^{7}$ Trabajadora Social. Departamento de Psiquiatría, Facultad de Medicina, Universidad de Antioquia. \\ E-mail: patomon7@hotmail.com
}

Received $16^{\text {th }}$ May 2005/Sent for Modification $11^{\text {th }}$ August 2005/Accepted $28^{\text {th }}$ September 2005

\begin{abstract}
Objectives Describing the socio-demographic and clinical characteristics of a group of individuals who committed suicide in the city of Medellín between 2000 and 2003; identifying possible groups within the suicides' socio-demographic and clinical characteristics.

Methods The sample consisted of 108 individuals who had committed suicide in Medellín; psychological autopsy was carried out and their characteristics were described. Multiple correspondence analysis was used for identifying the different groups.

Results $50 \%$ of the individuals were aged less than 29 and 79,4\% were male. The most frequently employed method for committing suicide was hanging (47,2 \%); 68,5 \% had expressed a wish to die and 35,2\% had previously attempted suicide. Three axes were identified for expressing the socio-demographic and clinical characteristics.

Conclusions The characteristics found in this study were similar to those reported in studies carried out in Colombia and other countries. Suicide was more frequent amongst younger people in the group being studied, this being consistent with the national tendency. The groups observed in multiple correspondence analysis were in line with clinical observations and can be used for designing prevention strategies. However, further analytical studies
\end{abstract}


REVISTA DE SALUD PÚBLICA • Volumen 7 (3), Noviembre 2005

are required for determining the actual risk factors and using them as the starting point for a prevention programme.

Key Words: Suicide, prevention, control, Psychology, Medellín (source: $\mathrm{MeSH}, \mathrm{NLM})$.

\section{RESUMEN \\ Características del suicido en Medellín, Colombia}

Objetivos Describir las características sociodemográficas y clínicas de un grupo de individuos que fallecieron por suicidio en la ciudad de Medellín entre 2000 y 2003 , e identificar posibles agrupaciones dentro de las características sociodemográficas y clínicas de los individuos suicidios.

Métodos Se tomó una muestra de 108 individuos que murieron por suicidio en Medellín, se realizó autopsia psicológica y se describieron sus características. Para identificar las posibles agrupaciones se realizó análisis de correspondencias múltiples.

Resultados El $50 \%$ de los individuos estudiados tenían una edad menor de 29 años y el 79,4 \% pertenecían al sexo masculino. El método de suicidio más frecuente fue el ahorcamiento (47,2\%), el 68,5\% habían manifestado deseos de morir y el 35,2 \% intentaron suicidarse previamente. Se identificaron tres ajes, cada uno con dos agrupaciones de características sociodemográficas y clínicas.

Conclusiones Se encontraron características similares a estudios descriptivos previos realizados en nuestro país y en otros lugares del mundo. En este grupo el suicidio ocurrió con más frecuencia en jóvenes, similar a la tendencia nacional. En el análisis de correspondencias múltiples se observaron agrupaciones coherentes con lo observado en la clínica, que pueden utilizarse para el diseño de estrategias de prevención. Sin embargo, se requieren estudios analíticos que permitan precisar los factores de riesgo y establecer efectivos programas de prevención

Palabras Clave: Suicidio, prevención, control, Psicología, Medellín (fuente: DeCS, BIREME)

\footnotetext{
$\mathrm{S}$ uicide is defined as being the act or instance of taking one's own life intentionally and voluntarily, with the full knowledge of the lethality of such an attempt (1). Suicide is becoming more important due to the increased mortality caused by it. However, the reported incidence is not very reliable, since it continues being a stigmatised act (2). It has been estimated that around 800000 people die by suicide around the world each year (3). The rates of incidence in Colombia in 1981, 1985, 1995 and 1999 were 3, 3, 5, 4 and 5 suicides per 100000 inhabitants per year, respectively. Since 1999 the figures have remained stable. The mortality rate for suicide in Colombia in 2003 was 4,4 per 100000 inhabitants per year. Bucaramanga had the
} 
greatest incidence of suicide amongst Colombia's largest department capital cities (i.e. having more than 1000000 inhabitants), with 9 per 100000 inhabitants per year and Barranquilla had the lowest rate with 4 per 100000 inhabitants per year. Medellín has constantly returned figures of 6 per 100000 inhabitants per year during the last five years (4).

The incidence of suicide varies amongst different countries and regions; the same occurs with the victims' characteristics. The best way of establishing such characteristics is by psychological autopsy, with which an individual's biographical and psychopathological aspects can be reconstructed through interviewing family members and friends and reviewing personal and medical documents $(5,6)$. This method has been employed when carrying out studies in Colombia in Bogotá and on the Atlantic Coast; depression and limited and narcissistic personality disorders were predominantly found to have been diagnosed in the former and depression was also most frequently found in the latter $(7,8)$.

These types of study have not been carried out so far in Medellín but they should be carried out for the regional variations which could present the phenomenon. Knowledge of the victims' characteristics is useful when proposing a hypothesis about the possible risk factors and designing prevention strategies which might be more suitable for the population. The present study was thus aimed at describing the socio-demographic and clinical characteristics of a group of individuals who committed suicide in Medellín between 2000 and 2003. It also identified possible groupings within the socio-demographic and clinical characteristics of suicide victims. Such groupings could be useful for designing and setting up specific programmes for the prevention of suicide.

\section{METHODS}

A convenience sample was taken from the 484 suicides occurring between 2000 and 2003 in the city of Medellín and its metropolitan area. 320 families were contacted by phone; 111 of them (34,7\%) decided to participate, 67 (20,9\%) could not be located because their phone numbers were defunct, 142 $(44,4 \%)$ families refused to participate and $3(0,01 \%)$ were excluded after being interviewed because it was not clear how the person had died (i.e. the cause of death). A medical-legal examination carried out at the Instituto de Medicina Legal established whether suicide was being dealt with.

The Universidad de Antioquia's Medicine Faculty Ethics Committee and the Research Committee from the Instituto Nacional de Medicina Legal reviewed and approved the protocol before any procedure was undertaken. In- 
formation was collected from people after giving a complete and detailed explanation about the origin and purpose of the project; the informed consent form was read to family members who then gave their written authorisation. Interviews were conducted using an instrument designed for such end by psychiatrists (CP, JG, GL, JD and CZ) who has been trained in applying it once the criteria to be evaluated had been standardised. At least two significant family members were interviewed (having first degree of consanguinity and who had lived with the individual) according to international recommendations. Another family member was called upon in the case of incongruity appearing in the information (6).

The variables studied were divided into four groups: socio-demographic, personal and family, psychopathological and vital adverse events.

The socio-demographic variables included: civil state (married, separated or divorced, widow/widower, single or living with a particular person), years of schooling, being unemployed, income (number of minimum wages), living alone, having children and participating in religious activities.

Personal and family parameters included: previous attempts at committing suicide, manifesting the desire to die, incapacitating physical disease, having consulted a non-psychiatric doctor during the month prior to death and a history of suicide and/or attempts at committing suicide in first degree of consanguinity family members.

Psychopathological variables included: mental disturbance diagnosed by psychological autopsy according to the Diagnostic and Statistical Manual for Mental Disorders (DSM-IV-TR) revised text criteria (9), antecedents of having undergone treatment and psychiatric hospitalisation.

Vital adverse events occurring during the six months prior to death were classified as being: the presence of any adverse event, the death of a loved one, separation, the deceased having problems with her/his own children, job-loss, economic difficulties and being informed of a serious disease.

Statistical analysis

SPSS-10.0 software was used for creating a database; statistical analysis employed frequencies and percentages for qualitative data and means of central tendency and dispersion for quantitative data. 
SPAD-N-3.5 software was used for identifying categories amongst the suicides' sociodemographic and clinical characteristics. Multivariate analysis was done by using the multiple correspondence method, allowing individuals', variables' or a variable's values to be grouped when data was categorical. A graphical representation of the association between categorical variables two to two meant that proximity between individuals could be analyzed in terms of similarity and proximity between modes of different variables in terms of association $(10,11)$. Categorical variables were used in this analysis; neither illustrative nor continuous variables were incorporated in this analysis.

\section{RESULTS}

$79,4 \%$ of the 108 people included in this study were male and $20,6 \%$ female. $50 \%$ of the population were aged over 29 when they committed suicide (19 to 42 interquartile age range). Half the population had had 8 years of schooling (5 to 11 interquartile age range). More than $50 \%$ of the cases were earning less than half a minimum monthly wage ( 0 minimum and 11 maximum). The other sociodemographic characteristics considered can be seen in Table 1.

Table 1. The sociodemographic characteristics of a group of people who committed suicide in the city of Medellín, 2000 to 2003

\begin{tabular}{|c|c|}
\hline Sociodemographic characteristics & $\begin{array}{c}\text { Suicides } n=108 \\
(\%)\end{array}$ \\
\hline \multicolumn{2}{|l|}{ Civil state: } \\
\hline - $\quad$ married & $21(19,4)$ \\
\hline - divorced or separated & $11(10,2)$ \\
\hline - $\quad$ widow/widower & 0 \\
\hline - $\quad$ single & $55(50,9)$ \\
\hline living with someone & $21(19,4)$ \\
\hline Living alone & $14(13)$ \\
\hline Having children & $49(45,4)$ \\
\hline Participating in religious activities & $48(44,4)$ \\
\hline Being unemployed & $30(27,8)$ \\
\hline
\end{tabular}

The methods employed for committing suicide were: 51 hanged themselves (47,2 \%), 24 used a firearm (22,2 \%), 17 poisoned themselves (15,7 $\%), 7$ threw themselves from a high place (6,5 \%), 3 used a sharp instrument $(2,8 \%)$ and 6 used other means (5,6\%), including setting fire to themselves, injecting air, throwing themselves from an automobile and drowning.

More than half (68,5 \%) had expressed a desire to die: 63 (58,3 \%) had stated this verbally and 17 (15,7\%) in writing; 38 (35,2\%) had previously attempted suicide, the mean being 0 ( 0 minimum and 6 maximum). 23,1 \% of 
the population had family antecedents of suicide and 26,9 \% had attempted suicide.

Regarding medical antecedents, 35 (32,4 \%) had consulted a non-psychiatric doctor during the month prior to committing suicide and 18 (16,7\%) had had incapacitating physical disease.

Table 2 shows the frequency of different psychiatric diagnoses made via psychological autopsy. There was a marked presence of psychiatric disorder in 97 people (89,8\%), but only 11,1\% had received psychiatric treatment, 25 $(23,1 \%)$ had been treated by a GP and $2(1,9 \%)$ by a psychologist. Nine people $(8,3 \%)$ had undergone some psychiatric hospitalizations during the year prior to committing suicide. Personality disorders were found in 18 (16,7 \%), including limited disorder in 7 (6,5\%), schizoid in 4 (3,7 \%), antisocial in 3 (2,8 \%), dependent in 2 (1,9\%) and schizo-typical disorder in 1 $(0,9 \%)$.

Table 2. The psychopathological characteristics of group of people who committed suicide in the city of Medellín, 2000 to 2003

\begin{tabular}{|c|c|}
\hline Psychopathological characteristics & $\begin{array}{c}\text { Suicides } \mathrm{n}=108 \\
(\%)\end{array}$ \\
\hline Psychiatric disorder (I) & $97(89,8)$ \\
\hline - major depressive episode & $67(62)$ \\
\hline - substance abuse or dependency & $59(54,6)$ \\
\hline Alcohol & $46(42,6)$ \\
\hline Cocaine & $15(13,9)$ \\
\hline Marihuana & $26(24,1)$ \\
\hline Benzodiazepines & $9(8,3)$ \\
\hline Inhalants & $2(1,9)$ \\
\hline opium-based substances & $2(1,9)$ \\
\hline - schizophrenia and other psychotic disorders & $8(7,4)$ \\
\hline - adaptive disorder & $4(3,7)$ \\
\hline - personality change due to frontal lesion & $1(0,9)$ \\
\hline - dysthymic disorder & $1(0,9)$ \\
\hline Personality disorder & $18(16,7)$ \\
\hline Psychiatric treatment & $12(11,1)$ \\
\hline Psychiatric hospitalisation during the last year & $9(8,3)$ \\
\hline
\end{tabular}

The results of Medicina Legal's examination for psychoactive substances in urine and blood during necropsy were negative in 61 individuals (56,1\%), positive in 32 (29,9\%) and no examination was carried out for the other 15 $(14 \%)$.

Vital adverse events had been presented during the six months prior to the deaths of 83 individuals (76,9 \%); the types of vital event can be seen in Table 3. 
Multiple correspondence analysis (based on the histogram of own values) was subjected to an interpretation having three axes. The following groupings were defined after analyzing the contributions and coordinates of the different values for each variable on each axis:

Table 3. Vital adverse events during the six months prior to death in a group of individuals who committed suicide in the city of Medellín, 2000 to 2003

\begin{tabular}{lc}
\multicolumn{1}{c}{ Event } & Suicides \\
\hline The presence of any adverse event & $83(76,9)$ \\
The death of a loved one & $23(21,3)$ \\
Separation & $33(30,6)$ \\
Problems with own children & $8(7,4)$ \\
Job-loss & $11(10,2)$ \\
Economic difficulties & $24(22,2)$ \\
Being informed of a serious disease & $7(6,5)$ \\
\hline
\end{tabular}

- Axis 1 explained 7,8 \% of variance. It was observed when analyzing the values for the coordinates on this axis and the graph that individuals diagnosed as having a psychotic disorder by psychological autopsy, a history of psychiatric treatment or who had not suffered from a major depressive episode, previously attempted suicide or expressed a desire for death, were separated towards the positive pole. Individuals diagnosed by psychological autopsy as suffering from major depressive disorder, were being treated by a GP, had previously attempted suicide, had expressed their desire for death, had suffered adverse vital events during the six months prior to their death or had consulted a non- psychiatric doctor during the month before committing suicide were found to be towards the negative pole.

- Axis 2 explained $6,8 \%$ of variance. This axis had a positive pole of individuals who were: separated or divorced, older adults, adults with their own children, people who did not participate in religious activities, had been informed of serious disease and who had died from poisoning or had thrown themselves from a height. Single individuals, young people, people without children or having limited personality disorder were at the negative extreme.

- Axis 3 explained 6,6 \% of variance. Males living with a partner, unemployed people, those who had had economic difficulties or affective separation during the previous six months, disorders due to substance abuse, used a firearm to commit suicide or presented positive results in the psychoactive substances examination were separated towards the positive pole. Females, people having problems with their children or hanged 
themselves when committing suicide were found towards the negative pole.

\section{DISCUSSION}

This was a descriptive study of clinical and sociodemographic characteristics pertaining to a sample of 108 people committing suicide between 2000 and 2003 in the city of Medellín. It has the limitations inherent in the psychological autopsy method which have been recognized by other authors, such as the biased memory of those being interviewed who possibly overvalue psychopathological details and vital events when someone dies by committing suicide $(6,12)$. Convenience sampling was used in this investigation; a large percentage of individuals who were eligible to participate in the study could not be found or family members declined to participate, meaning that the sample is not representative and the results cannot be generalized.

This sample of individuals reflected the national trend for suicide to occur more frequently in the younger population (4). It was thus necessary to investigate which elements play a predominant role in leading this group to commit suicide. This is especially important when it is taken into account that suicide produced 64343 lost years of useful life in Colombia during 2003, signifying great economic and social detriment. Its predominance in young people could be a reflection of Colombia's underdevelopment and the despair caused by the lack of opportunities, as some authors have mentioned that the peaks of age in suicide are related to economic development $(13,14)$.

A large percentage of the population being studied had poor working conditions and low wages as more than half of them were unemployed or underemployed receiving scant remuneration. Such socio-economic conditions have been observed in other studies on the topic and it is probable that they constitute a risk factor $(15,16)$.

$62 \%$ of the studied individuals were single, divorced or separated; more than half of them did not have children, which could mean that there is a frequent lack of affective ties within this population.

Participation in religious activities has been considered as protecting people against committing suicide because it takes advantage of social support, morally prohibiting it, giving a sense of vital purpose and providing specific cognition (e.g. the belief that adverse events result from God's will and must be accepted as such) (17). 65,6 \% of the suicides being studied in the sample 
had not been actively practicing their religion; this merits analytical study showing religion's protective role in the population of Medellín.

The methods chosen for committing suicide did not coincide with those reported in other studies; this may have been due to problems related to selecting the sample (4).

$32,4 \%$ of the individuals had consulted a GP, highlighting the importance of evaluating and managing the risk of a person committing suicide when a patient attends primary consultation, even though this may not be the given motive for consulting. Personnel working in primary attention and mental health services must take into consideration that a large percentage of suicides have expressed their desire to die and almost $90 \%$ have some sort of psychiatric disorder (the most frequent being depression and consumption of psychoactive substances).

A large group of victims presented family antecedents of attempting to commit suicide or actually committing suicide, coinciding with results from other studies and thereby leading to the possibility of a family component being considered in this event (18-20).

Three axes were considered in multivariate analysis, proving to be important when considering designing and establishing programmes aimed at preventing and treating attempted suicide. Individuals suffering from mental disorder were observed on the first axis; at one extreme were those suffering from a psychotic disorder who were being given psychiatric treatment and had no antecedents of attempted suicide and at the other extreme were patients suffering from depression, being treated by a GP and who expressed a desire to die. This axis highlights the importance of mental pathology and its suitable treatment in preventing suicide, from both the specialised and primary attention points of view. Mental health specialists must always consider patients suffering from psychotic disorders as being potential suicides. Primary attention services must be capable of suitably managing patients and have sufficient infrastructure for dealing with psychiatric pathology, particularly depression.

Adults older than 40 were observed on the second axis at one extreme who (in spite of having children) seemed to have few affective or religious ties and did have health problems. At the other extreme were younger people, having few affective bonds and unstable personalities. Characteristics which could have been associated with individuals' age were noticeable on this axis, above all when it is taken account that, according to studies concerning risk factors from different parts of the world, there is a peak during youth and an- 
other during old age $(3,13,14)$. Prevention strategies should be based on social wellbeing sectors for older adults, offering better living conditions, as well as preventative approaches aimed at the younger population and attempt psychological management of individuals suffering from dysfunctional personality features.

Males were observed at one pole on the third axis suffering from disorders arising from substance abuse, having economic difficulties and instable working conditions; prevention strategy here must take social sectors and working conditions into account, as well as preventing addiction and managing it. The other pole of the third axis was constituted by women having problems with their children, making family and individual intervention important so that this group of women acquires suitable tools for resolving such conflicts.

Similar characteristics were found to those of previous descriptive studies carried out in Colombia $(21,22)$ and other parts of the world. Multiple correspondence analysis revealed coherent groupings with that observed in clinical practice and could be used for designing prevention strategies. However, analytical studies are required so that true risk factors can be specified and, in turn, leading to establishing effective programmes for preventing and controlling attempted suicide.

Acknowledgements. This work was financed by the Instituto Colombiano para el Desarrollo de la Ciencia y la Tecnología (COLCIENCIAS) (contract 0183-04-12896) and the Instituto Nacional de Medicina Legal. We would like to thank Jason Garry for translating the text.

\section{REFERENCES}

1. Organización Mundial de la Salud. Clasificación Internacional de Enfermedades CIE-10. Madrid: Organización Mundial de la Salud; 1992.

2. World Health Organization. The World health report: 2001. Mental health: new understanding, new hope. Geneva, Switzerland: World Health Association; 2001.

3. Organización Mundial de la Salud. Informe mundial sobre la violencia y la salud: resumen. Washington, DC: Organización Mundial de la Salud; 2002.

4. Instituto Nacional de Medicina Legal y Ciencias Forenses, Centro de Referencia Nacional sobre Violencia. Forensis 2003. Datos para la vida. Herramienta para la interpretación, intervención y prevención del hecho violento en Colombia. Bogotá, DC: Panamericana Formas e Impresos SA; 2004.

5. Cavanagh JT, Carson AJ, Sharpe M, Lawrie SM. Psychological autopsy studies of suicide: a systematic review. Psychol Med 2003; 33:395-405. 
6. Cooper J. Ethical issues and their practical application in a psychological autopsy study of suicide. J Clin Nursing 1999; 8:467-475.

7. Ceballos-Ospino GA. Características de las personas que consumaron suicidio en la ciudad de Santa Marta (Colombia) durante el año 2002: un informe de casos. Boletín electrónico Psicología Clínica y de la Salud. 2004 (Internet) Disponible: www.monografias.com/trabajos14/suicide/suicide.shtml. Consulted December 2004.

8. Jiménez I, Morales M, Gelves C, Villamil D, Jiménez D, Cárdenas M et al., Analisis del suicidio a través de autopsia psicológica (Bogotá).

Rev Col Psiquiatria 1998; 27:197-211.

9. American Psychiatric Association. DSM-IV-TR: diagnostic and statistical manual for mental disorders. Revised text. Washington DC: Masson; 2000.

10. Escofier B, Pages J. Análisis factoriales simples y múltiples. Objetivos, métodos e interpretación. Bilbao: Dunod ; 1990.

11. Lebart L, Morineau A, Piron C. Statistique exploratoire multidimensionelle. Paris: Dunod ; 1995.

12. Isometsa ET. Psychological autopsy studies: a review. Eur Psychiatry 2001; 16:379-385

13. Lester D. The distribution of sex and age among completed suicides: a cross-national study. Int J Soc Psychiatry 1982; 28:256-260.

14. Schmidkte A. Perspective: suicide in Europe. Suicide Life Threat Behav 1997; 27:127-136.

15. Agerbo E, Nordentoft M, Mortensen PB. Familial, psychiatric, and socioeconomic risk factors for suicide in young people: nested case-control study. BMJ 2002; 325:74.

16. Artazcoz L, Benach J, Borrell C, Cortés I. Unemployment and mental health: understanding the interactions among gender, family roles, and social class. Am J Public Health 2004; 94:82-88.

17. Range LM, Leach MM, McIntyre D, Posey-Deters PB, Marion MS, Kovac SH et al., Multicultural perspectives on suicide. Aggression and violent behavior 1999; 4:413-430.

18. Chiu HF, Yip PS, Chi I, Chan S, Tsoh J, Kwan CW et al. Elderly suicide in Hong Kong: a case-controlled psychological autopsy study. Acta Psychiatr Scand 2004; 109:299-305.

19. Marusic A, Roskar S, Hughes RH. Familial study of suicidal behaviour amongst adolescents in Slovenia. Crisis 2004; 25:74-77.

20. Qin P, Agerbo E, Mortensen PB. Suicide risk in relation to socioeconomic, demographic, psychiatric and familial factors: a national register-based study of all suicides in Denmark, 1981-1997. Am J Psychiatry 2003; 160:765-772.

21. Calvo JM, Sánchez R, Tejada P. Prevalencia y factores asociados a ideación suicida en estudiantes universitarios. Rev Salud Pública 2003; 5(2): 123-143.

22. Sánchez R, Orejarena S, Guzmán Y. Características de los suicidios en Bogotá: 1985-2000. Rev Salud Pública 2004; 6(3): 217-234. 
